\title{
The ability of postgraduate students to diagnose and treat migraine and tension-type headache: A hospital-based survey.
}

\footnotetext{
1. MBBS, FCPS (Neurology) Assistant Professor Neurology PUMHS Nawabshah.

2. MBBS, M.D (Neurology) Professor Neurology Muhammad Medical College Mirpurkhas.

3. MBBS, FCPS (Neurology) Assistant Professor Neurology LUMHS Jamshoro.
}

Correspondence Address: Dr. Awais Bashir Larik Department of Neurology PUMHS Nawabshah. dr.awaisbashir@gmail.com

Article received on: 21/08/2020

Accepted for publication: 24/10/2020

\begin{abstract}
Awais Bashir Larik ${ }^{1}$, Shaheen Ahmed Mughal ${ }^{2}$, Muslim Ali Lakhiar ${ }^{3}$
ABSTRACT... Objective: The purpose of this study was to assess the ability of postgraduate medical students whether they can diagnose migraine and tension-type headache according to the International Headache Society criteria and whether they had an adequate clinical knowledge for the management of these headaches. Study Design: Cross Sectional Study. Setting: Departments of Neurology, PUMHS, Nawabshah and LUMHS, Jamshoro. Period: March and April 2018. Material \& Methods: A questioner was designed outlining three options for the diagnosis of Migraine and Tension Type Headache (TTH) and the students were asked to pick the correct option which is based on the International Headache Society (IHS) criteria. In addition, a few more questions were incorporated relating to the management of these headaches, confidence in making the diagnosis, knowledge of most common type of headache, need for neuroimaging, presence of childhood migraine and the role of genes in causing migraine. Data was analyzed by using SPSS version 18. Results: A total of 73 postgraduate students responded to the questionnaire. Among them 21 were enrolled in MD and 52 were enrolled in FCPS training program. For migraine and TTH diagnostic criteria only $34 \%$ and $19 \%$ were able to pick the correct answers respectively. Although there answers were incorrect $65.8 \%$ students were confident about their diagnosis. Majority (58.9\%) thought TTH as the most common headache and $11 \%$ thought migraine is the commonest. Most of the students $90.4 \%$ would go for neuroimaging in selected cases and the remaining $9.6 \%$. Thought neuroimaging is indicated in every case of headache. In response to have you ever seen a child with migraine in $71 \%$ the response was NO. As far the question is there a role of genes in causing migraine $63 \%$ said YES while 37\% thought there is NO role of genes in Migraine. Choice of drugs for acute and prophylactic treatment was also noted. Conclusion: The ability of postgraduate medical students to diagnose and treat migraine and tension-type headache was found to be less than satisfactory. There is a need for designing headache-specific CME programs for the postgraduate students so that their diagnostic and treatment abilities can be improved.
\end{abstract}

Key words: $\quad$ Diagnosis, Headache, Migraine, Postgraduate Students.

Article Citation: Larik AB, Mughal SA, Lakhiar MA. The ability of postgraduate students to diagnose and treat migraine and tension-type headache: A hospital-based survey. Professional Med J 2021; 28(6):907-913. https://doi.org/10.29309/TPMJ/2021.28.06.6016

\section{INTRODUCTION}

Migraine and Tension-type headache (TTH) are the most common primary headache disorders prevalent in the general population. ${ }^{1}$ Primary headaches cause considerable disability leading to limitations in performing daily activities together with profound negative impact on social and professional life. ${ }^{2,3}$ Headache is also a common cause of seeking emergency medical care. A large study evaluating the common causes of visit to an emergency department revealed that around two-third of the visits were for a primary headache disorder. ${ }^{4}$ More distressing being the migraine headache. According to a large nationwide study approximately $18 \%$ females and $6 \%$ males suffer from migraine..$^{5}$ In terms of disease burden and Disease-Adjusted Life Years (DALY) migraine ranks third among all the neurological diseases having disabling consequences. ${ }^{6}$ The economic burden for migraine is also quite high. The annual costs for migraine are over one billion dollars per year and migraine costs American employers 13 billion dollars per years due to absence and reduced productivity at work. ${ }^{7}$ 
Headache is also common in Pakistan. There are reports highlighting the prevalence of headache in adults ${ }^{8}$ as well as in children. ${ }^{9}$ and other professionals. ${ }^{10}$ A study from rural Sindh has also reported disability and reduced quality of life among migraine suffers. ${ }^{11}$ It is interesting to note that a significant proportion of medical students suffer from TTH and migraine. ${ }^{12}$ It is of grave concern that while medical students suffer from headache they do not take proper medication nor they seek timely consultation. ${ }^{12}$ If our medical professionals do not manage their own headache properly we wonder how they going to treat a case with headache while doing independent practice. Since the underdiagnosis of headache and related disorders remains a burning issue ${ }^{13,14}$ it is imperative that our trainee postgraduates students (PGs) do have a basic knowledge of diagnosing and treating common type of headaches. The International Headache Society (IHS) has provided diagnostic criteria for the diagnosis of migraine and TTH. ${ }^{15}$ To our knowledge no previous local study has critically examined the diagnostic ability of PGs especially in the light of recent IHS classifications and definitions. ${ }^{15}$ The purpose of this study was to assess the ability of PGs whether they can diagnose migraine and TTH according to IHS criteria and whether they have a basic knowledge of various treatment options that are available for the management of these headache.

\section{MATERIAL \& METHODS}

The study was conducted at the Departments of Neurology, Peoples Medical University of Medical and Health Sciences (PUMHS), Nawabshah and Liaquat University of Medical and Health Sciences Jamshoro (LUMHS) Sindh during the period 1.3.2018 to 30.4.2018. The study was approved by ethical committee (Letter no. 134/2018). Both FCPS and MD trainee doctors (PGs) who were enrolled in their respective program were included in the study. A questionnaire was designed especially for this study. The questionnaire comprising three options two of which were incorrect and one correct based on the International Headache Society (IHS) diagnostic criteria for migraine and similarly three options for TTH two incorrect and one correct and each student was asked to pick the correct option according to their own knowledge. In another two open ended questions the PGs were given the task of writing the most appropriate drugs prescribed for the management of acute migraine and for prophylactic therapy in migraine. Further close ended questions pertaining to their decision making abilities like ordering CT/MRI brain, degree of their self confidence in diagnosing the type of headache, which is the most common headache (Migraine or TTH), whether pediatric migraine occurs (yes or no) and is there a role of genetics in causing migraine (yes or no) were also included.

Before commencement of the study, Informed consent was taken from every student before collection of the data. All students meeting the inclusion criteria of either sex or age were included in the study. After collection of data analyses were conducted by using Statistical Package for the Social Sciences (SPSS) version 16. Frequencies and percentages calculated for categorical data like gender, program and year of residence and for remaining questions. Cross tabulation were applied to check association between year of residency, program of study and an IHS diagnostic criteria of migraine and TTH by applying chi-square test. SPSS 19.0 windows were used for data analysis.

\section{RESULTS}

A total of 73 postgraduate students filled out the questioner. Among them 31 (42.5\%) were male and $42(57.5 \%)$ were female (Figure-1). Of the 73 postgraduate students 21 (28.8\%) were enrolled in MD (Medicine) program and 52 (71.2\%) in FCPS program. Year-wise breakdown for first, second, third and fourth year postgraduate students was $31(42.5 \%), 23(31.5 \%), 6(8.2 \%)$ and $13(17.8 \%)$ respectively (Figure-2). The basic characteristics of study participants are shown in Table-I.

When asked to pick the correct option for IHS diagnostic criteria for Migraine and Tension type headache 25 (34\%) and 19 (26\%) gave correct answer for Migraine and TTH respectively while 
$48(66 \%)$ and 54 (74\%) responded incorrectly (Figure-3 \& 4).

Whether neuroimaging (CT/MRI) should be done in all cases of primary headache, 66 (90.4\%) answered No while 7 (9.6\%) answered Yes and whether neuroimaging be done in selected cases $66(90.4 \%)$ answered Yes and 7 (9.6\%) answered No. How confident they were in diagnosing the primary headache $48(65.8 \%)$ were confident, 23 $(31.5 \%)$ were less confident and $2(2.7 \%)$ very confident. Majority of the students $43(58.9 \%)$ thought TTH was most common type, 22(30.1\%) thought migraine as the most common whereas $8(11 \%)$ considered migraine + TTH as the most common primary headache. When asked have you ever seen a child with migraine $52(71.2 \%)$ responded No and 21 (28\%) said Yes. Whether there is a role of genes in causing migraine 46(63\%) answered Yes and 27(37\%) answered No (Table-II). As for the management of acute migraine the majority $(73 \%)$ favored NSAID while $51 \%$ favored Triptans (Table-III). For prophylactic therapy in migraine $34 \%$ favored Beta blockers and 33\%Antiepileptics. Alarmingly 19\% picked Triptans for the prophylaxis of migraine. In 15\% the answer was don't know (Table-IV). As far the correct or incorrect responses there were no significant differences among male and female students. FCPS students had edge over M.D students on IHS criteria for TTH only and LUMHS students had edge over PUMHS students on IHS criteria for migraine headache only. (Table-V).

\begin{tabular}{|c|c|c|}
\hline Basic Information & \multirow{2}{*}{\multicolumn{2}{|c|}{$\mathbf{N}(\%)$}} \\
\hline Center & & \\
\hline LUMHS & \multicolumn{2}{|c|}{$36(49.3 \%)$} \\
\hline PMC & \multicolumn{2}{|c|}{$37(50.7 \%)$} \\
\hline \multicolumn{3}{|l|}{ Gender } \\
\hline Male & \multicolumn{2}{|c|}{$31(42.5 \%)$} \\
\hline Female & \multicolumn{2}{|c|}{42 (57.5\%) } \\
\hline \multicolumn{3}{|l|}{ Training Program } \\
\hline MD & \multicolumn{2}{|c|}{$21(28.8 \%)$} \\
\hline FCPS & \multicolumn{2}{|c|}{$52(71.2 \%)$} \\
\hline \multicolumn{3}{|l|}{ Year of Program } \\
\hline First Year & \multicolumn{2}{|c|}{31 (42.5\%) } \\
\hline Second Year & \multicolumn{2}{|c|}{$23(31.5 \%)$} \\
\hline Third Year & \multicolumn{2}{|c|}{$6(8.2 \%)$} \\
\hline Fourth Year & \multicolumn{2}{|c|}{$13(17.8 \%)$} \\
\hline \multicolumn{3}{|l|}{ Age in years } \\
\hline $\begin{array}{l}\text { Mean } \\
\text { Std. Deviation }\end{array}$ & \multicolumn{2}{|c|}{$27.21 \pm 2.91$} \\
\hline \multicolumn{3}{|c|}{ Table-I. Basic characteristics of study group. } \\
\hline \multicolumn{2}{|c|}{ Medication Group } & $N(\%)$ \\
\hline \multicolumn{2}{|l|}{ NSAID } & $53(73 \%)$ \\
\hline Paracetamol & & $7(10 \%)$ \\
\hline \multicolumn{2}{|l|}{ Antiemetics } & $7(10 \%)$ \\
\hline \multicolumn{2}{|l|}{ Ergotamine } & $9(12 \%)$ \\
\hline \multicolumn{2}{|l|}{ Triptans } & $37(51 \%)$ \\
\hline \multicolumn{2}{|l|}{ Beta Blockers } & $8(11 \%)$ \\
\hline \multicolumn{2}{|l|}{ Tricyclic Antidepressants } & $13(18 \%)$ \\
\hline \multicolumn{2}{|c|}{$\begin{array}{l}\text { Selective Serotonin Reuptake inhibitors } \\
\text { (SSRI) }\end{array}$} & $2(3 \%)$ \\
\hline \multicolumn{2}{|l|}{ Antiepileptic } & $5(7 \%)$ \\
\hline \multicolumn{2}{|l|}{ Flunarazine } & $2(3 \%)$ \\
\hline \multicolumn{2}{|l|}{ Gabapentine } & $2(3 \%)$ \\
\hline \multicolumn{2}{|l|}{ Opiods } & $2(3 \%)$ \\
\hline \multicolumn{2}{|l|}{ Benzodiazepam } & $1(1 \%)$ \\
\hline Calcium Channel Block & & $1(1 \%)$ \\
\hline Don't Know & & $2(3 \%)$ \\
\hline & & $151(207 \%)$ \\
\hline
\end{tabular}

Table-II. Response for acute migraine therapy.

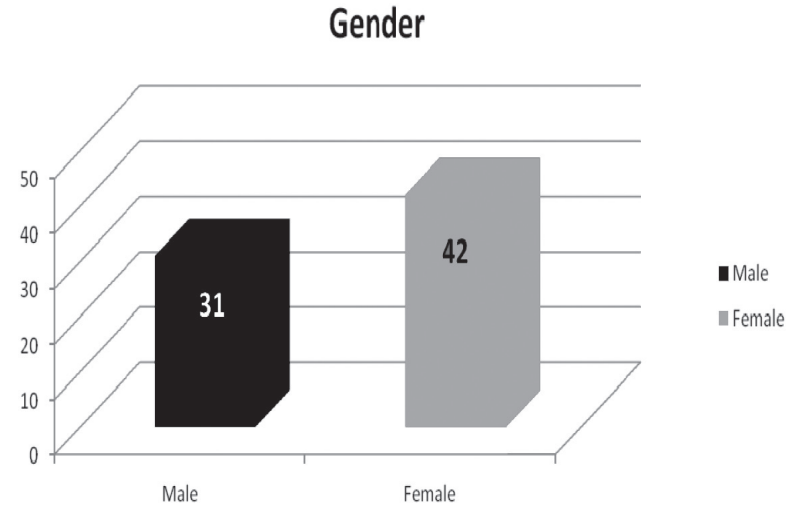

Figure-1. Gender distribution of study group.

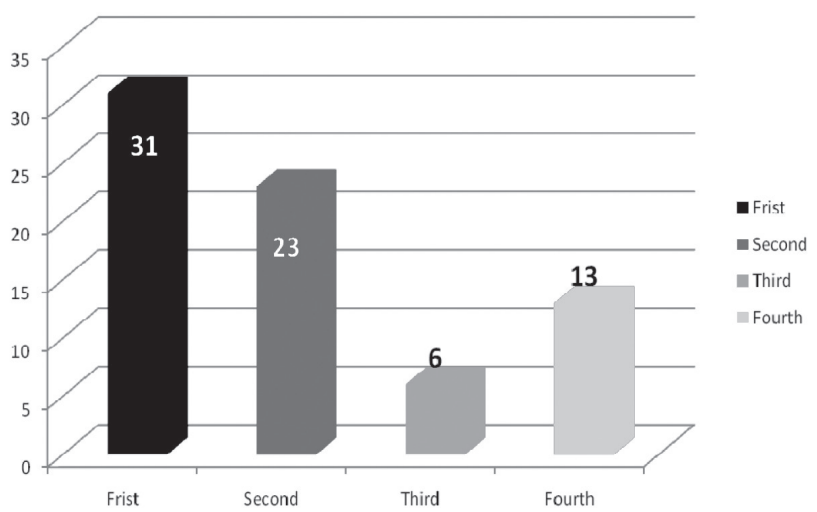

Figure-2. Level of postgraduate students. 
IHS diagnostic criterion of migraine headache

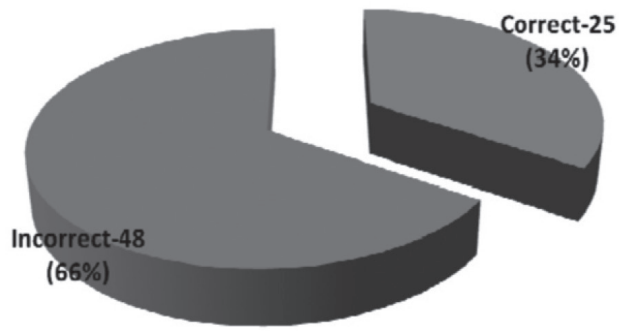

Figure-3. Response rate for migraine diagnostic criteria.

\section{Multiple Response Questions}

\begin{tabular}{|l|c|}
\hline \multicolumn{1}{|c|}{ Medication Group } & N (\%) \\
\hline NSAID & $12(16 \%)$ \\
\hline Antiemetics & $10(14 \%)$ \\
\hline Triptans & $14(19 \%)$ \\
\hline Ergotamine & $2(3 \%)$ \\
\hline Beta Blockers & $25(34 \%)$ \\
\hline Antiepileptic & $24(33 \%)$ \\
\hline Tricyclic Antidepressants & $8(11 \%)$ \\
\hline SSRI & $5(7 \%)$ \\
\hline Calcium Channel Blockers & $6(8 \%)$ \\
\hline Gabanergic & $6(8 \%)$ \\
\hline Anti-Psychotics & $11(15 \%)$ \\
\hline Muscle Relaxant & $1(1 \%)$ \\
\hline Don't Know & $48 \%)$ \\
\hline Table-III. Response for & \\
\hline
\end{tabular}

IHS diagnostic criterion of tension type headache

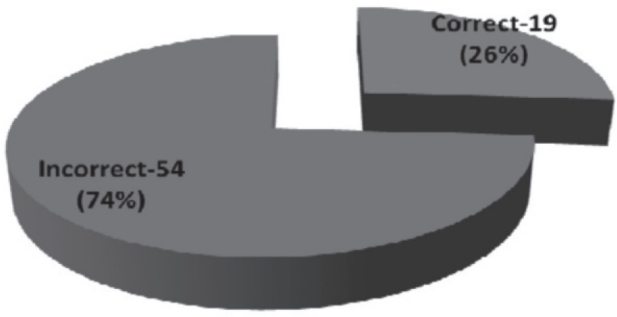

Figure-4. Response rate for TTH diagnostic criteria.

\section{Multiple Response Questions}

\begin{tabular}{|l|c|}
\hline \multicolumn{1}{|c|}{ Questions } & n=73 \% \\
\hline How would you investigate in primary headache? \\
\hline Neuroimaging in All cases \\
\hline Yes & $7(9.6 \%)$ \\
\hline No & $66(90.4 \%)$ \\
\hline Neuroimaging in selected cases \\
\hline Yes & $66(90.4 \%)$ \\
\hline No & $7(9.6 \%)$ \\
\hline $\begin{array}{l}\text { How Confident you are in making diagnosis of } \\
\text { primary headaches? }\end{array}$ \\
\hline Less Confident & $23(31.5 \%)$ \\
\hline Confident & $48(65.8 \%)$ \\
\hline Very Confident & $2(2.7 \%)$ \\
\hline Does pediatric migraine exist? \\
\hline Yes & $41(56.2 \%)$ \\
\hline No & $32(43.8 \%)$ \\
\hline Have you ever seen a child with migraine? \\
\hline Yes & $21(28.8 \%)$ \\
\hline No & $52(71.2 \%)$ \\
\hline Which one is more common Headache? \\
\hline Migraine & $8(11.0 \%)$ \\
\hline Tension Type & $43(58.9 \%)$ \\
\hline Both & $22(30.1 \%)$ \\
\hline Is there any role of genetics in migraine? \\
\hline Yes & $46(63.0 \%)$ \\
\hline No & $27(37.0 \%)$ \\
\hline
\end{tabular}

\begin{tabular}{l|l} 
Response & MD
\end{tabular}

N

$\%$

FCPS

$\mathbf{N}$ $\%$

IHS diagnostic criterion of migraine Headache

\begin{tabular}{|l|c|c|c|c|}
\hline Correct & 8 & $38 \%$ & 17 & $33 \%$ \\
\hline Incorrect & 13 & $62 \%$ & 35 & $67 \%$ \\
\hline IHS diagnostic criterion of Tension type Headache & & 17 & $33 \%$ \\
\hline Correct & 2 & $10 \%$ & 35 & $67 \%$ \\
\hline Incorrect & 19 & $90 \%$ & \\
\hline
\end{tabular}

Table-V. Training Program wise response rate for Migraine \& TTH. 


\section{DISCUSSION}

For an accurate clinical diagnosis certain criteria are applied so that proper diagnosis can be made. Since the diagnosis of various headache types such as migraine and TTH headache is mainly clinical, the International Headache Society (IHS) has laid down the diagnostic criteria and guidelines for the accurate diagnosis. ${ }^{15}$ During clinical assessment of a patient with headache those physicians who follow these criteria are expected to perform better compared to those who do not follow the IHS criteria. That is what we intended to observe in our study. It is alarming to note that a greater proportion of PGs performed poorly on the given tasks. Majority (66\%) could not answer the correct IHS criteria for migraine and $74 \%$ could not answer TTH criteria correctly. Knowing that migraine and TTH are so prevalent in the general population and that our PGs could hardly apply a correct IHS criteria for proper diagnosis is noteworthy as well as worrisome. The question arise whether this dismal scenario is confined only in the institutions we study or is it same across the country. A multicenter study in major institutions across the country would probably yield an answer to this question.

Since the local studies on the same issue among the PGs are not available for comparison the other alternative approach remained with us was to look at more or less similar studies carried out on the general practitioners or family physicians. International studies where primary care physicians were assessed has also revealed marked deficiencies in making proper diagnosis of various headache types. In a study from Turkey ${ }^{16}$, almost $90 \%$ of the primary care physician could not apply correctly the IHS criteria for the diagnosis of migraine. In another study from Saudi Arabian ${ }^{17}$, out of $55 \%$ responders covering demographic, factual and practical aspects of headache disorders $45 \%$ of the primary health care physicians had inadequate knowledge. Furthermore, in a recent survey conducted in different provinces of Pakistan 62\% practicing family physicians were able to distinguish between TTH and migraine headache on the basis of history alone. ${ }^{18}$ This is quite encouraging but not surprising since FPs are more involved and experienced in general practice compared to PGs. With the same analogy, comparing investigating and treatment preferences among Pakistani FPs and PGs would not be ideal given the limitation pointed out above on lack of secondary data for comparison. However, since both the FPs and PGs are product of the same medical education system looking at their management approaches would yield some information on how far they are coherent. For instance, only 35\% FPs thought Triptans were the most effective treatment for acute migraine ${ }^{18}$ whereas $51 \%$ of PGs in our study had the same view. In a broader sense these figures are acceptable. But the alarming part is when $19 \%$ of FPs choose topiramate for treating acute migraine, $12 \%$ were not aware of these medications and almost $6 \%$ thought they are not indicated in migraine prophylaxis. ${ }^{18}$ Similar blunders were made by the PGs as well. For example, 19\% PGs in our study choose triptans and $16 \%$ PGs picked NSADs for prophylactic therapy in migraine and $15 \%$ did not know what to say. Given the standard practicing guidelines these figures are not acceptable. Since patients well being is at stake these shortcomings among PGs in particular need to be addressed seriously.

Having highlighted the lacunae or the weaknesses, obviously the best way forward is better education. Published reports indicate that the proper training in this area helps to overcome the shortcomings to a greater extent. Arranging continuing medical education (CME) program specifically for headache diagnosis and care has shown tremendous improvement in diagnostic abilities of primary care physicians. In an American study ${ }^{19}$ the CME program coined "Brainstorm" presentation was developed to cover the essential elements of migraine care. Improvement in scores from pre-presentation to post-presentation had a significant immediate impact on the knowledge of the participating physicians. Similarly in a 2-day headache education program for GPs diagnostic accuracy and choice of proper treatment increased from $56 \%$ to $81 \% .{ }^{20}$ The same study ${ }^{20}$ proposed to adopt such educational program that may further be extended to the university level. 
While clinical assessment of any patient is an integral part of postgraduate medical training, it is imperative that certain areas of significance such as headache-care should not remain out of focus. In a most relevant study describing the status of headache education in medical schools all responders believed that headache including migraine is an important subject to teach and two-third of the responders found headache education inadequate in the medical schools. $^{21}$ Such state of affair is also evident in our study. Therefore there is a need to stress for $\mathrm{CME}$ programs on headache diagnosis and treatment for PGs. Further research is needed to know precisely what other measures beside CME programs can be helpful particularly for the PGs who are destined to become the future consultants.

\section{CONCLUSION}

The ability of postgraduate medical students to diagnose and treat migraine and tension-type headache was found to be less than satisfactory. There is a need for designing headache-specific CME programs for the postgraduate students so that their diagnostic and treatment abilities can be improved.

\section{Copyright@ 24 Oct, 2020.}

\section{REFERENCES}

1. WHO/ Neurological disorders: Public health challenges. World Health Organization; 2006.

2. Leonardi M. The global burden of migraine: Measuring disability in headache disorders with WHO classification of functioning, disability and health. J Headache Pain 2005; 6:429-40.

3. Stewart WF, Lipton RB, Simon D. Work-related disability: Results from the American Migraine Study. Cephalalgia 1996; 16:231-38.

4. Goldstein JN, Camargo Jr CA, Pelletier AJ, Edlow JA. Headache in United States emergency departments: Demographics, work-up and frequency of pathological diagnosis. Cephalalgia 2006; 26(6):68490.

5. Stewart WE, Lipton RB, et al. Prevalence of migraine in United States. Relation to age, income, race, and other socio demographic factors. JAMA 1992; 267:6469.
6. Manzoni GC, Stovner LJ. Epidemiology of headache. Handb Clin Neurolo Netherland; 2010; 97:3-22.

7. Hu X, Markson L, et al. Disability and economic costs of migraine in the United States: A population based approach. Arch Int Med 1999; 159:813-18.

8. Harekar AD, Harekar AA, Ahmed A. et al. The burden of headache disorders in Pakistan: Methodology of a population-based nationwide study and questionnaire validation. J Headache Pain 2013; 14(1):73.

9. Siddiqui SJ, Shamim SM, Hashmi AM. Prevalence and patterns of headache in school going children in Karachi. JPMA 2006; 56(5):215-7.

10. Naveed S, Hameed A, Sharif N. Awareness and prevalence of migraine, survey based study in Karachi. Intnl J Bio Sci App 2014; 1(14):157-61.

11. Mughal SA, Memon AQ, Lal B. Underdiagnoses of migraine and the impact of headache-related disability on the quality of life of patients. Med Forum 2012; 23(2):6-9.

12. Noor T, Sajid A. Frequency and predisposing factors among students of medical college of Karachi. JPMA 2016; 66:159.

13. Tepper SJ, Lipton RB, Diamond S, Reed M, et al. Migraine diagnosis and treatment: Results from the American Migraine Study II. Headache 2001; 41:63845.

14. Kernick D, Stapley S, Hamilton W. GPs classification of headache: Is primary headache underdiagnosed? BR J Gen Pract England 2008; 58:102-4.

15. Headache classification committee of the international headache society (IHS). The International Classification of Headache Disorders, $3^{\text {rd }}$ Edition (beta version). Cephalalgia 2013; 33:629-808.

16. Gultekn M, Balsi E, Ismailogullari S et al. Awareness of migraine among primary care physician in Turkey: A regional study. Arc Neurpsychiatr 2016.DOI: 10.5152/ npa2016.19228.

17. Alzahrani $F$, Hmoud $M$, Khayat $H$ et al. Knowledge of primary healthcare physicians about headache disorders: A cross-sectional study. Quality in Primary Care 2006; 24(2):83-6.

18. Malik A, Awan S, Sonawall A, et al. Awareness and approach to headache: $A$ survey of family physicians in Pakistan. Pak J Neurol Sci 2018; 13(4):5-10. 
19. Patwardhan MB, Samsa GP, Lipton RB, Matchar DB. Changing physician knowledge, attitudes, and beliefs about migraine: Evaluation of a new educational intervention. Headache 2006; 46(5):73241.

20. Karli N, Zarifoglu M, Eres S, et al. The impact of education on the diagnostic accuracy of tensiontype headache and migraine: A prospective study. Cephalalgia 2007; 27:41-45.
21. Kommineni $M$, Finkel $A$. Teaching headache in America: Survey of neurology chairs. Headache 2005; 45:862-65.

\begin{tabular}{|c|l|l|l|}
\hline \multicolumn{4}{|c|}{ AUTHORSHIP AND CONTRIBUTION DECLARATION } \\
\hline Sr.\# & \multicolumn{1}{|c|}{ Author(s) Full Name } & \multicolumn{1}{|c|}{ Contribution to the paper } & Author(s) Signature \\
\hline 1 & Awais Bashir Larik & $\begin{array}{l}\text { Concept, Study design, Data } \\
\text { collection, References. }\end{array}$ \\
\hline 2 & Shaheen Ahmed Mughal & $\begin{array}{l}\text { Conceopt, Study design, } \\
\text { Interpretation, Data analysis. } \\
\text { Concept, Study design, Data } \\
\text { collection, References. }\end{array}$ & Mushimm alli \\
\hline 3 & Muslim Ali Lakhiar & Mur \\
\hline
\end{tabular}

